RESEARCH PAPER

J. Food Sci. \& Technol. Nepal, Vol. 7 (81-85), 2012

ISSN: 1816-0727

\title{
Effect of Combinative Pretreatments on Cellulose-to-Glucose Conversion of Empty Palm Fruit Bunch (EFB)
}

\section{YAKINDRA PRASAD TIMILSENA ${ }^{1,2,3 *}$ and NICOLAS BROSSE ${ }^{2}$}

\author{
${ }^{1}$ Asian Institute of Technology, 58 Moo 9, Km. 42, Paholyothin Highway, KlongLuang, Pathumthani 12120, Thailand \\ ${ }^{2}$ Université de Lorraine, Laboratoire d'Etude et de Recherche sur le MAteriau Bois, BP 70236, 54506 Vandoeuvre-lès-Nancy \\ cedex, France \\ ${ }^{3}$ Department of Food Technology and Quality Control Babarmahal, Kathmandu
}

\begin{abstract}
Various methods of pretreatments were investigated to their effect on cellulose to glucose conversion efficiency on enzymatic hydrolysis of a tropical agro-industrial waste residue (empty palm fruit bunch, EFB). Four different kinds of combinative pretreatments (autohydrolysis with and without naphthol, dilute acid prehydrolysis, soda prehydrolysis and enzymatic prehydrolysis) were tested for delignification during the first and the second steps of pretreatment. Each prehydrolysis step was seconded by the organosolv delignification with the same conditions of pretreatment. It was observed that all the combinative methods were far more efficient in delignification and enzymatic hydrolysis ability as compared to its one step counter parts. The combinative pretreatment method involving dilute acid prehydrolysis followed by organosolv delignification revealed the best result with respect to lignin removal and enzymatic hydrolysis. The resultant pulp contained very low Klason lignin ( $5 \%)$ with high sugar conversion ratio (64\% total reducing sugars).
\end{abstract}

Keywords: Lignocellulosic waste, Empty palm fruit bunch (EFB), Enzymatic hydrolysis, Lignin

\section{Introduction}

Large amount of lignocellulosic wastes are produced as a by-product of food and agriculture processing installations. Lignocellulose wastes are accumulated in large quantities in municipal and industrial areas and cause serious environmental problems. Sugarcane bagasse, apple pomace, grape pomace and empty palm fruit bunch (EFB), corncob, wheat straw and brewer's spent grains are some industrial by-products which are either going unutilized or poorly utilized. Bagasse, wheat straw and EFB are currently being used in heating the boiler system in the industrial sectors. These wastes when combusted produce carbon dioxide and carbon monoxide resulting in environmental pollution (Jun et al., 2008). Many municipalities have faced great problem in managing such kind of wastes. However, due to their chemical composition based on sugars and other compounds of interest, they could be utilized for the production of a number of value added products, such as ethanol, food additives, organic acids, enzymes, and others. Therefore, besides the environmental problems caused by their accumulation in the nature, the nonuse of these materials constitutes a loss of potentially valuable sources (Mussatto and Teixeira, 2010).

Palm oil industry generates a large quantity of residues and wastes in the form of empty fruit bunch, palm kernel shells, trunk of the plant, fibre, leaves and others. All these waste products contain large amount of lignocellulosic polymers in addition to some sugars and lipid portions. Among them EFB is considered as the promising feedstock for the synthesis of biobased products owing to its high content of sugar polymers (75-80\%) and 20-25\% lignin (Deraman, 1995).

\footnotetext{
*Corresponding author. E-mail address: yakendra.timilsena@gmail.com
}

Modern biorefinery concept targets the separation and valorization of all the three polymers of lignocellulosic feedstocks. Sugar polymers (cellulose and hemicellulose) are to be converted to monomeric form prior to utilization in the food, chemical or material manufacturing whereas lignin can find use in its native form in the synthesis of degradable films, polymers and adhesive (El Hage et al., 2009 ; Brosse et al., 2011).

Various kinds of combinative pretreatment have been described by different researchers for different kinds of biomasses. It has been demonstrated that auto-hydroloysis, dilute sulphuric acid prehydrolysis or enzymatic prehydrolysis prior to the organosolv treatment not onlyallowed a better recovery of xylans but also enhanced the dissolution and recovery of lignin and the digestibility of the remainingcellulose by enzymes (El Hage et al., 2010; Obama et al., 2012). In two step pretreatments technique, processing can be carried out at low severity which ultimately reduces the formation of degradation products like furfural and hydroxymethyl furfural (HMF). It is also important because harsh condition of pretreatment (usually thermal processes) causes difficulty in removal of lignin owing to lignin repolymerization through formation of a carbonium ion intermediate, which promote the formation of new linkages leading to the formation of more resistant intermediate structures ( $\mathrm{Li}$ and Lundquist, 2000 ). Addition of catalytic amount of carbonium ion scavengers like 2-naphthol and other reactive phenols during hydrothermal treatments has been reported to improve the lignin extractability (Wayman and Lora, 1978).

In this study, empty palm fruit bunch (EFB) was tested for the effect of different pretreatment methods and enzymatic 
hydrolysability. The main objective is to compare the pretreatment methods and assess the cellulose to glucose conversion of the variously treated EFB pulp.

\section{Materials and Methods}

Empty palm fruit bunch (EFB) was collected from Malaysia, milled to a particle size of 1-3 mm using a Wiley mill and stored at $5^{\circ} \mathrm{C}$. All chemical reagents used in this study were purchased from Sigma Aldrich and VWR (France) and used as received. Dried matter contents were determined using a moisture balance, KERN MRS 120-3 Infra-red moisture meter.

Autohydrolysis- Empty palm fruit bunch (1-3 mm particle size, $20 \mathrm{~g}$ native dry matter) was loaded into a 0.6 -L stainless steel pressure Parr reactor with a Parr 4842 temperature controller (Parr Instrument Company, Moline, IL) and was supplemented with an appropriate amount of deionized water to make a final solid to liquid ratio of $1 / 9$, taking into account the moisture content of the sample. The mixture was heated at $150^{\circ} \mathrm{C}$ with continuous stirring for $8 \mathrm{~h}$ (time zero was set when the preset temperature was reached with heating rate of $5 \mathrm{~K} /$ $\min )$. At the end of each reaction, the reactor was cooled and the liquid phase was recovered by filtration throughWhatman No 4 filter paper. Solid residue was washed with $70^{\circ} \mathrm{C}$ water $(3$ $\mathrm{x} 50 \mathrm{ml}$ ) and a portion of solid residue and liquid were stored in a freezer at $-5^{\circ} \mathrm{C}$ before analysis.

Organosolv treatment- Empty palm fruit bunch $(200 \mu \mathrm{m}$ particle size, 25 grams dry weight of native or autohydrolysed biomass) was mixed with $80 \%$ aqueous ethanol $\left(\mathrm{EtOH} / \mathrm{H}_{2} \mathrm{O}\right.$ : $8 / 2, \mathrm{v} / \mathrm{v}$ ) and $0.5 \%$ (based on raw material dry mass) sulphuric acid as a catalyst. The mixture was heated at $170^{\circ} \mathrm{C}$ for 60 min. The solid-to-liquid ratio used was 1: 8. The reaction was carried out in a $0.6 \mathrm{~L}$ stainless steel pressure Parr reactor with a Parr 4842 temperature controller (Parr Instrument Company, Moline, IL). The reaction mixture was heated at a rate of 5 $\mathrm{K} / \mathrm{min}$ with continuous stirring. At the end of the treatment, the pretreated biomass was washed with $60^{\circ} \mathrm{C}$ ethanolwater $(8: 2,3 \times 50 \mathrm{~mL})$ and air-dried overnight. The washes were combined, and three volumes of water were added to precipitate the ethanol organosolv lignin (EOL), which was collected by centrifugation at $4000 \mathrm{x}$ gfor $10 \mathrm{~min}$ and then air-dried. A portion of each the solid residue and the liquid was separated and stored in a freezer at $-5^{\circ} \mathrm{C}$ before analysis.

Cellulose extraction- Holocellulose was isolated from the untreated feedstockby repeatedly treating with a mixture of acetic acid and sodium chlorite until the sample had a very low Klason lignin content $(<1 \%)$. The holocellulose sample $(1 \mathrm{~g})$ was further treated with $50 \mathrm{~mL}$ of $17.5 \% \mathrm{NaOH}$ for 30 $\mathrm{min}$ at $25^{\circ} \mathrm{C}$. Fifty $\mathrm{mL}$ of deionized water was added and the resulting slurry was stirred at $25^{\circ} \mathrm{C}$ for $30 \mathrm{~min}$. The resulting cellulose was filtered, washed successively with $50 \mathrm{~mL}$ of $1 \%$ acetic acid in water and with $100 \mathrm{~mL}$ of deionized water and then dried in an oven at $40^{\circ} \mathrm{C}$ overnight.
Enzymatic hydrolysis (cellulose-to-glucose conversion)Enzymatic hydrolysis of empty palm fruit bunch (raw and pretreated) was performed using Celluclast ${ }^{\circledR} 1.5 \mathrm{~L}$ (E.C. 3.2.1.4) from Trichoderma reesei supplemented with $\beta$-glucosidase preparation (Novozyme $188 \AA$, E.C. 3.2.1.21) from Aspergillus niger at a loading of 44 IFPU and 25 IU per $g$ cellulose respectively. Both enzyme preparations were purchased from Novozymes (Bagsværd, Denmark) and stored as $-5^{\circ} \mathrm{C}$ before use. Enzymatic hydrolyses were performed at $2 \%$ (cellulose w/v) in $100 \mathrm{~mL}$ of $50 \mathrm{mM}$ acetate buffer, $\mathrm{pH}$ 5.0. The reaction mixtures were incubated at $50^{\circ} \mathrm{C}$ in a rotary shaker at $150 \mathrm{rpm}$, sampled periodically and centrifuged at $4000 \mathrm{rpm}$ to remove the insoluble materials before further analysis. Glucose contents of the aqueous phase were quantified using glucose oxidase-peroxidase-chromogen reagent (RTUTM manufactured by bio Merieux, France). Total reducing sugars were also determined using DNS method (Miller, 1959). Hydrolysis data are averages from duplicate experiments.

Analytical procedures- A KERN MRS 120-3 Infra-red moisture analyser (drying at $105^{\circ} \mathrm{C}$ to constant weight) was used for moisture determination. Extractable fats were determined by extracting untreated biomass $(50 \mathrm{~g})$ with dichloromethane (DCM, 1L), using a Soxhlet apparatus (volume $=2 \mathrm{~L}$ ) for $6 \mathrm{~h}$ (about 36 extraction cycles).

Carbohydrate and lignin contents were measured on extractivefree material, ground to pass a 40-mesh screen, according to the laboratory analytical procedure (LAP) provided by the National Renewable Energy Laboratory (NREL). Samples were hydrolyzed with $72 \%$ sulfuric acid for $1 \mathrm{~h}$ and autoclaved after being diluted to $3 \%$ sulfuric acid through the addition of water. The autoclaved samples were filtered, and the dried residue was weighed to give the Klason lignin content. Monosaccharide contents in the filtrate were quantified using high-performance anion-exchange chromatography with pulsed amperometric detection (HPAEC PAD). The acid-soluble lignin content was determined from absorbance at $205 \mathrm{~nm}$ according to Lin and Dence (1992). In brief, the lignin content in the filtrate was calculated from the following expression of Beer's law: Lignin $(\mathrm{g} / \mathrm{L})=$ Absorbance $/ 110$.

High-performance anion-exchange chromatographySeparation and quantification of neutral sugars were performed using a Dionex ICS-3000 system consisting of a SP gradient pump, an AS autosampler, an ED electrochemical detector with a gold working electrode, an $\mathrm{Ag} / \mathrm{AgCl}$ reference electrode and Chromeleon version 6.8 (Dionex Corp., USA). A Carbopac PA1 (4 x $250 \mathrm{~mm}$, Dionex) column with a guard column (4 x $50 \mathrm{~mm}$, Dionex) was used as a stationary phase using isocratic conditions with $1 \mathrm{mM}$ sodium hydroxide as eluent. Eluents were prepared by dilution of a $46-48 \% \mathrm{NaOH}$ solution (PA S/4930/05 Fisher Scientific) in ultrapure water. All eluents were degassed before use by flushing with helium for $20 \mathrm{~min}$; subsequently they were kept under constant helium 
pressure (eluent degassing module, Dionex). After each run, the column was washed for 10 min with $200 \mathrm{mM} \mathrm{NaOH}$ and reequilibrated for $15 \mathrm{~min}$ with the starting conditions. Samples were injected through a $25-\mu \mathrm{L}$ full loop and separations were performed at $25^{\circ} \mathrm{C}$ at a rate of $1 \mathrm{~mL} / \mathrm{min}$. The pulse sequence for pulsed amperometric detection consisted of a potential of $+100 \mathrm{mV}(0-200 \mathrm{~ms}),+100 \mathrm{mV}$ integration $(200-400 \mathrm{~ms})$, $-2000 \mathrm{mV}(410-420 \mathrm{~ms}),+600 \mathrm{mV}(430 \mathrm{~ms})$, and $-100 \mathrm{mV}$ (440-500ms).

\section{Results and Discussion}

Raw material composition- The compositions of the untreated empty palm fruit bunch (EFB) are reported in the Table 1. It appears from the table that EFB is xylan-rich biomass with major components glucan, lignin and xylan. The cellulose contents $(\sim 48 \%)$ was almost double of xylan contents $(\sim$ $25 \%$ ). Comparison of the compositional data for untreated EFB biomass with the literatures data (Amin et al., 2010; Sabiha-Hanim et al., 2011) shows higher values of Klason lignin but glucans and xylans figures are slightly lower. Higher values of Klason lignin is mainly due to the higher presence of mineral and siliceous matters (Klason lignin includes ashes also). It shows that hemicellulose portion basically composed of arabinoxylan with a higher proportion of xylose than arabinose. This observation closely agrees with composition reported in literatures for most of the monocotyledons (Yoshida et al., 2008).

Table 1. Composition of untreated EFB

\begin{tabular}{|c|c|c|c|c|c|c|c|c|}
\hline $\begin{array}{c}\text { Klason } \\
\text { lignin }(\%)\end{array}$ & $\begin{array}{c}\text { Cellulose } \\
(\%)\end{array}$ & $\begin{array}{c}\text { Hemi- } \\
\text { cellulose } \\
(\%)\end{array}$ & $\begin{array}{c}\text { Glucans } \\
(\%)\end{array}$ & Xylans (\%) & $\begin{array}{c}\text { Arabinans } \\
(\%)\end{array}$ & $\begin{array}{c}\text { Galactans } \\
(\%)\end{array}$ & $\begin{array}{c}\text { Mannans } \\
(\%)\end{array}$ & Others $(\%)$ \\
\hline $22.9 \pm 0.2$ & $48.4 \pm 0.4$ & $28.5 \pm 0.3$ & $48.7 \pm 2.8$ & $25.2 \pm 0.8$ & $1.0 \pm 0.03$ & $0.6 \pm 0.01$ & $0.4 \pm 0.0$ & $0.6 \pm 0.02$ \\
\hline
\end{tabular}

It is demonstrated that EFB contains high proportion of cellulose and hemicellulose sugars suggestingits potential use for bioconversion processes such as biofuel, biogas or biochemical productions.

Prehydrolysis- Four different prehydrolysis methods were used. The experimental conditions were selected based on the literature data used earlier (El Hage et al., 2010). The compositions of the solid residues after autohydrolysis of the three substrates are given in Table 2. It has been shown that hemicellulose polysaccharides (mainly xylans) were depolymerized; $\sim 50 \%$ of the original xylans were removed from the pulp and solubilized during autohydrolysis without naphthol whereas $\sim 70 \%$ xylans removed during soda pretreatment.

Table 2. Composition of pulp after prehydrolysis

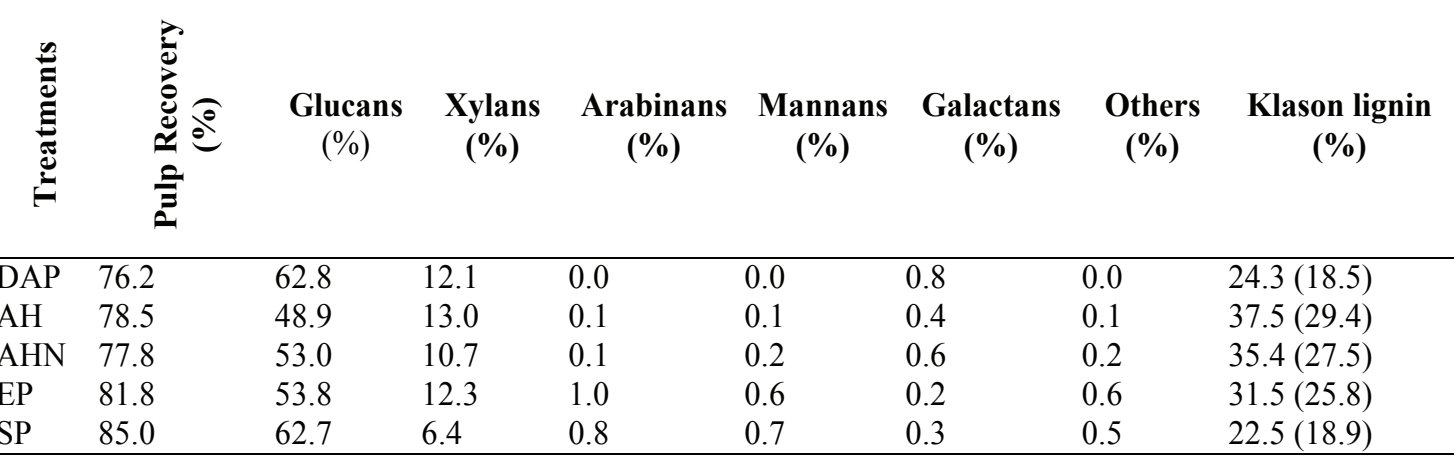

DAP: Dilute acid prehydrolysis, AH: Autohydrolysis, AHN: Autohydrolysis with 2-Naphthol, EP: Enzymatic Prehydrolysis, SP: Sodium hydroxide prehydrolysis, -Klason lignin includes ashes and proteins , - The values in the parentheses shows the KL content of the biomass considering the mass loss during prehydrolysis

The effect of prehydrolysis on lignin content was found insignificant. It showed that lignin is not removed during prehydrolysis in appreciable amount. Soda pretreatment showed the maximum effect on lignin removal as compared to other methods- only $\sim 19 \%$ Klason lignin was left in the pulp whereas autohydrolysed pulp revealed $\sim 29 \%$ Klason lignin content.
Organosolv and combinative pretreatments- The ethanol organosolv treatments (OS) were performed starting from the raw materials and from the prehydrolyzed pulp. The organosolv conditions used in the present study $\left(\mathrm{T}=170{ }^{\circ} \mathrm{C}\right.$, $\mathrm{t}=60 \mathrm{~min}, \mathrm{EtOH} / \mathrm{H}_{2} \mathrm{O}=0.80, \mathrm{H}_{2} \mathrm{SO}_{4}=0.5 \%$ ) were selected considering previously described studies (El Hage et al., 2010). The compositions of the pulps after organosolv (OS) 
Table 3. Composition of EFB after combinative pretreatment

\begin{tabular}{|c|c|c|c|c|c|c|c|c|}
\hline 氖 & 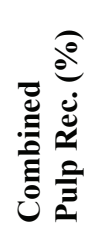 & 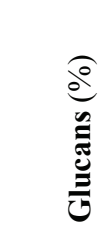 &  & 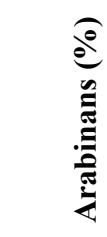 & 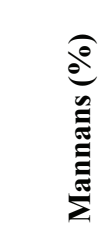 & 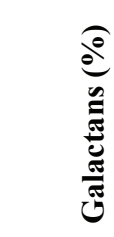 & 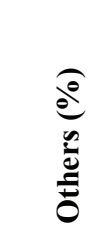 & 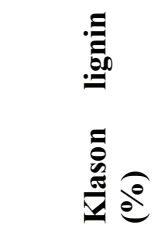 \\
\hline$\overline{\mathrm{OS}}$ & 75.9 & 50.2 & 27.1 & 0.5 & 0.4 & 0.1 & 0.4 & $21.3(16.0)$ \\
\hline DAPOS & 61.3 & 80.6 & 11.1 & 0.1 & 0.1 & 0.2 & 0.1 & $7.7(4.8)$ \\
\hline AHOS & 61.5 & 73.3 & 12.3 & 0.0 & 0.0 & 0.6 & 0.0 & $13.6(8.4)$ \\
\hline AHNOS & 59.6 & 76.3 & 13.8 & 0.0 & 0.0 & 0.6 & 0.0 & $9.2(5.5)$ \\
\hline EPOS & 68.2 & 63.5 & 18.4 & 0.3 & 0.3 & 0.0 & 0.3 & $17.2(15.9)$ \\
\hline SPOS & 69.0 & 63.5 & 18.4 & 0.3 & 0.3 & 0.0 & 0.3 & $17.2(11.7)$ \\
\hline
\end{tabular}

OS: Organosolv delignification of untreated biomass, DAPOS: Dilute acid prehydrolysis combined with organosolv delignification, AHOS: Autohydrolysis followed by OS delignification, AHNOS: Autohydrolysis with 2-Naphthol followed by OS delignification, EPOS: Enzymatic prehydrolysis followed by OS delignification, SPOS: Sodium hydroxide prehydrolysis followed by OS delignification - Klason lignin includes ashes and proteins -The values are $\%$ of the pulp recovered after combinative treatment- The values in the parentheses shows the KL content of the biomass considering the combined mass loss

and combinative treatments $(\mathrm{AH}+\mathrm{OS}, \mathrm{AHN}+\mathrm{OS}, \mathrm{EP}+\mathrm{OS}$, $\mathrm{DAP}+\mathrm{OS}, \mathrm{SP}+\mathrm{OS})$ are given in the Table 3 . The amounts of ethanol organosolv lignin (EOL, recovered through precipitation by addition of water in the black liquor, see experimental section) and Klason lignin contents in the pulps are reported in the Figure 1.

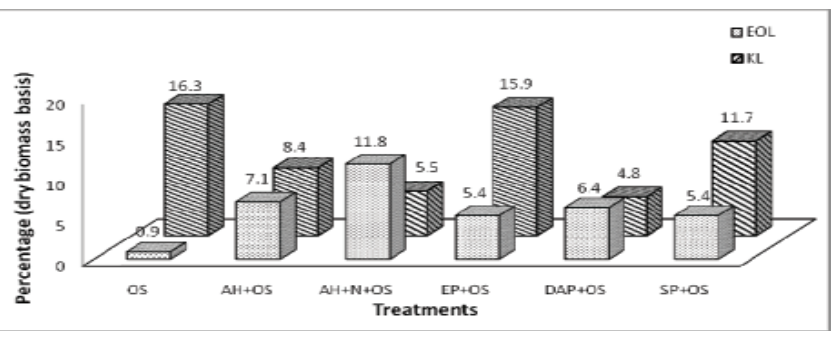

Figure 1. EOL \& KL Content of the pulp after organosolv delignification

For the single-step treatment performed without autohydrolysis (OS), a lowdelignification rate wasobserved. Indeed, the low severity reaction conditions used in this study for the organosolv treatment didn't act as an effective solubilizer of lignin. As expected, starting from autohydrolysed pulp $(\mathrm{O}+\mathrm{AH})$, higher amounts of EOL were recovered (7 to $12 \%)$ and larger parts of lignin were extracted leaving a lower lignin content in the pulps (5 to 16\%). The effect of enzymatic prehydrolysis was not promising, however, it is considered as more environmentally benign technique. It has already been reported that prehydrolysis improved the efficacy of organosolv processdue to weakening of the lignin seal and increased solubility of lignin in organic solvent (El Hage et al., 2010; Obama et al., 2012). It has been reported that the lignin deconstruction takes place during autohydrolysis through aryl-ether bonds cleavage resulting in easier delignification. It appears from Table 2 and Figure 1 that considerable improvement took place in delignification in presence of naphthol. Decrease of $\sim 30 \%$ of the Klason lignin content with naphthol was observed. Dilute acid prehydrolysis followed by organosolv process revealed the lowest value of Klason lignin. The reason is unclear but might be due to a high hydrolytic sensibility of EFB lignin in acidic medium.

\section{Enzymatic hydrolysis}

Enzymatic hydrolyses of the solid residue after pretreatments were performed using standard literature conditions (44 FPU of cellulase and $25 \mathrm{CBU}$ of $\beta$-glucosidase). The glucose and total reducing sugar recovered by enzymatic hydrolysis are reported in Figure 2. Untreated biomass yielded only 5\% glucose whereas the cellulose to glucose conversion is very less in case of the single step of pretreatment. Only 24\% glucose yield from autohydrolysed pulp and only $19 \%$ in case of dilute acid pretreated pulp.

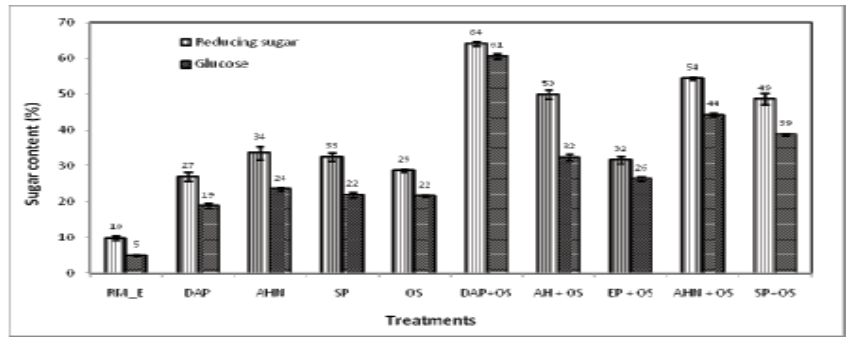

Figure 2. Cellulose to glucose conversion yield of different treated EFB pulps

The cellulose-to-glucose conversion was found substantially increased using combinative pretreatments; however, the 
effect of different combinative pretreatments is not same. Highest yield was observed in case of dilute acid pretreated pulp which was further subjected to organosolv delignification. It showed $61 \%$ conversion ratio. The effect of enzymatic prehydrolysis was very less on conversion process. The effect of naphthol was not substantial on enzymatic digestibility; however it showed some positive effect.

Dilute acid prehydrolysis followed of organosolv delignification demonstrated the best results. Although the exact reason is not clear, it could be due to higher deconstruction of EFB lignin in acidic medium within a certain $\mathrm{pH}$ range. It was also observed that large amount of lignin $(\sim 5-6 \%)$ was detected in the liquid stream which escaped the precipitation after organosolv process. It revealed that lignin was broken down into very small fragments in dilute acid prehydrolysed pulp which was difficult to recover by aqueous precipitation of liquid phase after organosolv process.

\section{Conclusion}

Empty palm fruit bunch (EFB), a by-product of palm oil industries, can serve as a promising feedstock for bioconversion processes owing to its substantially higher content of cellulose and comparatively lower lignin content. Food and agricultural waste serves as source of raw material for bio-conversion processes as they do not demand separate land, water, and energy requirements. They do not have food value as well. Fermentative and direct chemical conversion of glucose produced from cellulose can lead to production of different food products and organic chemicals. If the degradation products are separated and glucose can be isolated in pure form, it can find diverse use in food industries. On the other hand the hemicellulose and lignin can also be utilized in food industries. Presence of polyphenolic groups in lignin proposes its use as bio-antioxidant in different kinds of food preparations.

In this study, two-step combinative pretreatmentwhich involved prehydrolysis and organosolv process showed significantly better results in comparison to the single step pretreatment (either prehydrolysis or organosolv process only). The best result shown by dilute acid pre-hydrolyzed pulp in terms of delignification ability and enzymatic hydrolysability suggested that EFB lignin is more susceptible to the action of acids, however, the exact reason was not known.

\section{References}

Amin N. A. S., Ya'aini N., Misson M., Haron R. and Mohamed M. (2010). Enzymed Pretreated Empty Palm Fruit Bunch for Biofuel Production. Journal of Applied Sciences, 10 (12): 1181-1186.

Brosse N., Mohamad Ibrahim M. N. and Abdul Rahim A. (2011). Biomass to Bioethanol: Initiatives of the Future for Lignin. ISRN Materials Science, 1-10.
Deraman M., Ismail M. P. and Said M. Z. M. D. (1995). Young's modulus of carbon from a mixture of oil palm bunches and latex. Journal of Materials Science Letters, 14(11): 781-782.

El Hage R., Brosse N., Chrusciel L., Sanchez C., Sannigrahi P. and Ragauskas A. (2009). Characterization of milled wood lignin and ethanol organosolv lignin from Miscanthus.Polymer Degradation and Stability, 94(10): 1632-1638.

El Hage, R. Chrusciel L., Desharnais L. and Brosse N. (2010). Effect of autohydrolysis of Miscanthus x giganteus on lignin structure and organosolv delignification. Bioresour Technol., 101(23): 9321-9329.

Jun L. L., Ying W., Qiang Z., Xiang L. J., Guang Y. X. and Jun J. (2008). Wheat straw burning and its associated impacts on Beijing air quality. Science in China Series D: Earth Sciences, 51'(3): 403-414.

Li S. and Lundquist K. (2000).Cleavage of arylglycerol betaaryl ethers under neutral and acid conditions. Nord.Pulp pap. Res. J., 15: 292-299.

Lin S. Y. and Dence C. W. (1992).Methods in Lignin Chemistry. Springer-Verlag: Berlin Heidelberg.

Miller G. L. (1959). Use of dinitrosalicylic acid reagent for the determination of reducing sugars. Anal. Chem., 31, 426-428.

Mussatto S. I. and Teixeira J. A. (2010).Current Research, Technology and Education Topics in Applied Microbiology and Microbial Biotechnology. FORMATEX.

Obama P., Ricochon G., Muniglia L. and Brosse N. (2012). Combination of enzymatic hydrolysis and ethanol organosolv pretreatments: effect on lignin structures, delignification yields and cellulose-to-glucose conversion. Bioresour Technol., 112, 156-163.

Sabiha-Hanim, S., Noor, M. A. M., and Rosma, A. (2011). Effect of autohydrolysis and enzymatic treatment on oil palm (Elaeis guineensis Jacq.) frond fibres for xylose and xylooligosaccharides production. Bioresour Technol., 102(2), 1234-1239.

Wayman M. and Lora J. H. (1978). Aspen autohydrolysis. The effect of 2-naphthol and other aroatic compounds. TAPPI, 61(6):55-57.

Yoshida M., Liu Y., Uchida S., Kawarada K., Ukagami Y., Ichinose H., Kaneko S. Fukuda K. (2008). Effects of cellulose crystallinity, hemicellulose and lignin on the enzymatic hydrolysis of Miscanthus sinensis to monosaccharides. Biosci. Biotechnol. Biochem., 72(3): 805-810. 